\title{
Outcomes of conduction system pacing compared to right ventricular pacing as a primary strategy for treating bradyarrhythmia: systematic review and meta-analysis
}

\author{
Amr Abdin $^{1}$ (1) Suleman Aktaa ${ }^{2,3} \cdot$ Davor Vukadinović $^{1}$ - Elena Arbelo ${ }^{4,5,6} \cdot$ Harran Burri $^{7} \cdot$ Michael Glikson $^{8}$. \\ Christian Meyer $^{9} \cdot$ Theresa Munyombwe $^{2} \cdot$ Jens Cosedis Nielsen $^{10,11} \cdot$ Christian Ukena $^{1} \cdot$ Kevin Vernooy $^{12,13}$. \\ Chris P. Gale 2,3
}

Received: 9 May 2021 / Accepted: 16 August 2021 / Published online: 19 August 2021

(c) The Author(s) 2021

\begin{abstract}
Background Right ventricular pacing (RVP) may cause electrical and mechanical desynchrony leading to impaired left ventricular ejection fraction (LVEF). We investigated the outcomes of RVP with His bundle pacing (HBP) and left bundle branch pacing (LBBP) for patients requiring a de novo permanent pacemaker (PPM) for bradyarrhythmia.

Methods and results Systematic review of randomized clinical trials and observational studies comparing HBP or LBP with RVP for de novo PPM implantation between 01 January 2013 and 17 November 2020 was performed. Random and fixed effects meta-analyses of the effect of pacing technology on outcomes were performed. Study outcomes included all-cause mortality, heart failure hospitalization (HFH), LVEF, QRS duration, lead revision, atrial fibrillation, procedure parameters, and pacing metrics. Overall, 9 studies were included (6 observational, 3 randomised). HBP compared with RVP was associated with decreased HFH (risk ratio [RR] 0.68, 95\% confidence interval [CI] 0.49-0.94), preservation of LVEF (mean difference [MD] $0.81,95 \% \mathrm{CI}-1.23$ to 2.85 vs. $-5.72,95 \% \mathrm{CI}-7.64$ to -3.79 ), increased procedure duration (MD $15.17 \mathrm{~min}$, 95\% CI 11.30-19.04), and increased lead revisions (RR 5.83, 95\% CI 2.17-15.70, $p=0.0005$ ). LBBP compared with RVP was associated with shorter paced QRS durations (MD 5.6 ms, 95\% CI - 6.4 to 17.6) vs. (51.0 ms, 95\% CI 39.2-62.9) and increased procedure duration (MD $37.78 \mathrm{~min}, 95 \%$ CI 20.04-55.51).

Conclusion Of the limited studies published, this meta-analysis found that HBP and LBBP were superior to RVP in maintaining physiological ventricular activation as an initial pacing strategy.
\end{abstract}

Keywords Cardiac pacing $\cdot$ His-bundle pacing $\cdot$ Left bundle branch pacing $\cdot$ Clinical outcomes $\cdot$ Meta-analysis $\cdot$ Systematic review

\section{Introduction}

Permanent pacing with right ventricular stimulation is frequently used in patients with bradyarrhythmia, and recommended by current international guidelines because it is associated with improved clinical outcomes [1]. The extent of right ventricular pacing (RVP) varies between patients and many individuals tolerate a high proportion of RVP without complications [2-6]. However, chronic RVP may

Amr Abdin and Suleman Aktaa contributed equally.

Amr Abdin

amr.abdin@uks.eu

Extended author information available on the last page of the article cause electrical and mechanical desynchrony leading to impaired left ventricular ejection fraction (LVEF), mitral and tricuspid valve regurgitation and an increased risk of atrial fibrillation (AF) [2-7]. While the benefits of biventricular pacing (BiVP) over RVP in patients with reduced LVEF and atrioventricular (AV) block, who require ventricular pacing, is established [8], the optimal pacing strategy for those with normal or mildly reduced LVEF is less well understood.

Novel pacing technologies, such as His bundle pacing (HBP) and left bundle branch pacing (LBBP), have emerged to maintain physiological ventricular activation via the native His-Purkinje system [9-12]. However, there is limited information concerning the comparative effectiveness of those novel pacing strategies against RVP in patients with 
normal or mildly reduced LVEF $[10,11]$ and thus the optimal pacing method for this group of patients remains uncertain. Notably, both American and European guidelines recommend RVP as an initial pacing strategy for patients with normal or mildly reduced LVEF $[1,7]$. Therefore, we aimed to compare HBP and LBBP with RVP as an initial pacing strategy for patients requiring de novo permanent pacemaker implantation for bradyarrhythmia. This work was initiated after questions emerging during the development of the cardiac pacing quality indicators (QIs) for the 2021 European Society of Cardiology (ESC) Clinical Practice Guidelines on cardiac pacing and cardiac resynchronization therapy [1].

\section{Methods}

\section{Systematic review}

\section{Search strategy}

We conducted a systematic review of the published randomized controlled trials (RCTs) and controlled observational studies in accordance with the Preferred Reporting Items for Systematic Review and Meta-Analyses (PRISMA) statement [14], using MEDLINE and Embase via OVID @. The initial search strategy was developed in MEDLINE using keywords and Medical Subject Headings (MeSH) terms (Supplementary material, Table S1), and the final strategies were then developed using an iterative process incorporating findings from citations and grey literature search. We included the main publications of major studies from which our search obtained only sub-studies. The search was restricted to fulltext articles published in English between 01 January 2013 and 17 November 2020. The year 2013 was selected because it corresponds to the publication of the last ESC Clinical Practice Guidelines on cardiac pacing and cardiac resynchronisation therapy [1].

\section{Study selection}

We included studies that: [1] compared directly the effects of HBP or LBBP versus RVP, [2] evaluated adults ( $\geq 18$ years of age) with bradyarrhythmia and an indication for de novo permanent pacing, [3] reported at least one outcome of interest for comparison at implantation and at any point during the follow-up period, and [4] provided data that allowed the comparison between the study arms (i.e. means and standard deviations [SD] or medians and interquartile ranges [IQR]). When data by the same authors or the same institution in an overlapping period were identified, only the most recent results were considered. A reference manager software (Zotero) was used for duplicates removal and data management. Two reviewers (AA and SA) independently reviewed the abstracts of the identified articles against the predefined inclusion criteria. Disagreements were solved with discussion.

\section{Data extraction}

For the selected studies, two investigators (AA and SA) reviewed the full texts and used the same template to extract data relevant to the analysis on an Excel spreadsheet. The study design, as well as the sample size, pacing characteristics, duration of follow-up and primary endpoints were extracted as shown in Table1.

\section{Appraising the quality of the review studies}

Cochrane Risk of Bias Assessment was used to evaluate the quality of RCT (Supplementary material, Table S2), and Newcastle-Ottawa Scale Assessment for cohort studies (Supplementary material, Table S3). Due to the small number of included trials $(<5)$ for each comparison group, exploration of any potential publication bias was not performed.

\section{Statistical analysis}

The primary outcomes for the study were mortality and heart failure hospitalization (HFH). The secondary outcomes were changes in LVEF, AF occurrence, paced QRS (pQRS) complex duration, procedure duration, lead revision rates and pacing threshold. To compare outcomes between studies investigating RVP (control group) with studies investigating HBP and LBBP, we pooled the available data (number of events for dichotomous variables, and average value, standard deviation and sample size for continuous variables) for each outcome of interest from the included studies. Differences in events rates and average values for specific outcome among groups were determined and presented using Forest plots with corresponding 95\% confidence intervals (CI) for each study. The effect measure for dichotomous variables was quantified as risk ratios (RR), and for continuous variables was the mean difference (MD). Meta-analysis was conducted and the data from each study were pooled using fixed (Mantel-Haenszel, Rothman-Boice) or random effects (DerSimonian-Laird) model, as appropriate. Statistical heterogeneity between the trials was assessed using Cochran's $\mathrm{Q}$ test and Higgins $I^{2}$ statistic. Relevant statistical heterogeneity was present in cases where Cochran's Q test $p<0.05$ and $I^{2}>50 \%$, for which cases we used random-effects models. All statistical analyses were conducted using RevMan 5.3 software. All $p$ values were two-sided, with $p<0.05$ considered as significant. 
Table 1 Baseline characteristics of studies comparing, HBP, LBBP, and RVP as a primary pacing strategy

\begin{tabular}{|c|c|c|c|c|c|c|c|c|}
\hline Study & Study design & FU (months) & Pacing mode & $\begin{array}{l}\text { Number of } \\
\text { participants }\end{array}$ & $\begin{array}{l}\text { Indication for } \\
\text { pacing }\end{array}$ & $\begin{array}{l}\text { Primary end- } \\
\text { point }\end{array}$ & $\begin{array}{l}\text { Baseline EF } \\
(\%)\end{array}$ & $\begin{array}{l}\text { Pacing burden } \\
\%\end{array}$ \\
\hline $\begin{array}{l}\text { Catanzariti } \\
\text { et al. } 2013 \\
\text { [15] }\end{array}$ & $\begin{array}{l}\text { Observtional } \\
\text { crossover }\end{array}$ & 34.6 & HPB vs. RVP & 26 vs. 26 & $\begin{array}{l}\text { AV conduc- } \\
\text { tion disease } \\
\text { or SND }\end{array}$ & $\begin{array}{l}\text { LV dyssyn- } \\
\text { chrony and } \\
\text { function }\end{array}$ & $57.2+7.4$ & NA \\
\hline $\begin{array}{l}\text { Kronborg } \\
\text { et al. } 2014 \\
{[16]}\end{array}$ & $\begin{array}{l}\text { RCT crosso- } \\
\text { ver }\end{array}$ & 12 & HPB vs. RVP & 19 vs. 19 & AV block & LVEF & $\begin{array}{c}56 \pm 10 \text { vs. } \\
55 \pm 7\end{array}$ & $>99$ \\
\hline $\begin{array}{c}\text { Pastore et al. } \\
2016 \text { [18] }\end{array}$ & retrospective & 58 & HPB vs. RVP & 148 vs. 329 & AV block & $\begin{array}{l}\text { AF occur- } \\
\text { rence }\end{array}$ & $\begin{array}{c}62+7 \text { vs } \\
60+8\end{array}$ & NA \\
\hline $\begin{array}{l}\text { Vijayaraman } \\
\text { et al. } 2017 \\
\text { [17] }\end{array}$ & retrospective & 60 & HPB vs. RVP & 94 vs. 98 & $\begin{array}{l}\text { AV conduc- } \\
\text { tion disease } \\
\text { or SND }\end{array}$ & $\begin{array}{l}\text { Safety and } \\
\text { success rate } \\
\text { of HBP }\end{array}$ & $\begin{array}{c}55 \pm 8 \text { vs } \\
57 \pm 7\end{array}$ & $\begin{array}{l}59 \pm 43 \\
\text { vs } 57 \pm 45\end{array}$ \\
\hline $\begin{array}{l}\text { Abdelrahman } \\
\text { et al. } 2018 \\
\text { [12] }\end{array}$ & $\begin{array}{l}\text { Prospective } \\
\text { non-rand- } \\
\text { omized }\end{array}$ & 24 & HPB vs. RVP & 332 vs. 433 & $\begin{array}{l}\text { AV conduc- } \\
\text { tion disease } \\
\text { or SND }\end{array}$ & $\begin{array}{l}\text { death, } \mathrm{HFH} \text { or } \\
\text { upgrade to } \\
\text { BiVP }\end{array}$ & $\begin{array}{r}54.9 \pm 8.5 \mathrm{vs} \\
54.2 \pm 10.2\end{array}$ & $\begin{array}{l}54-58 \text { for both } \\
\text { groups }\end{array}$ \\
\hline $\begin{array}{l}\text { Wang et al. } \\
2019 \text { [20] }\end{array}$ & $\begin{array}{l}\text { Prospective- } \\
\text { randomized }\end{array}$ & 6 & $\begin{array}{l}\text { LBBP vs. } \\
\text { RVP }\end{array}$ & 66 vs. 65 & $\begin{array}{l}\text { AV conduc- } \\
\text { tion disease } \\
\text { or SND }\end{array}$ & $\begin{array}{l}\text { Depolariza- } \\
\text { tion-repo- } \\
\text { larization } \\
\text { indices }\end{array}$ & $\begin{array}{c}61.3 \pm 5.7 \text { vs } \\
62.1 \pm 6.3\end{array}$ & NA \\
\hline $\begin{array}{r}\text { Zhang et al. } \\
2019 \text { [19] }\end{array}$ & $\begin{array}{l}\text { Prospective- } \\
\text { randomized }\end{array}$ & 0 & $\begin{array}{l}\text { LBBP vs. } \\
\text { RVP }\end{array}$ & 20 vs. 21 & $\begin{array}{l}\text { AV conduc- } \\
\text { tion disease } \\
\text { or SND }\end{array}$ & $\begin{array}{l}\text { Immediate } \\
\text { clinical } \\
\text { outcomes }\end{array}$ & $\begin{array}{c}45.7 \pm 18.4 \text { vs } \\
65.9 \pm 4.1\end{array}$ & NA \\
\hline $\begin{array}{l}\text { Chen et al. } \\
2019 \text { [22] }\end{array}$ & $\begin{array}{l}\text { Prospective } \\
\text { non-rand- } \\
\text { omized }\end{array}$ & 3 & $\begin{array}{l}\text { LBBP vs. } \\
\text { RVP }\end{array}$ & 20 vs. 20 & $\begin{array}{l}\text { AV conduc- } \\
\text { tion disease } \\
\text { or SND }\end{array}$ & $\begin{array}{l}\text { ECG and } \\
\text { pacing char- } \\
\text { acteristics }\end{array}$ & $\begin{array}{c}60 \pm 10.6 \text { vs } \\
60.7 \pm 6\end{array}$ & NA \\
\hline $\begin{array}{l}\text { Cai et al. } 2019 \\
\text { [21] }\end{array}$ & $\begin{array}{l}\text { Prospective } \\
\text { non-rand- } \\
\text { omized }\end{array}$ & 0 & $\begin{array}{l}\text { LBBP vs. } \\
\text { RVP }\end{array}$ & 40 vs. 38 & SND & $\begin{array}{l}\text { Electrical and } \\
\text { mechanical } \\
\text { synchrony }\end{array}$ & $\begin{array}{l}>53 \text { in both } \\
\text { groups }\end{array}$ & NA \\
\hline
\end{tabular}

Baseline characteristics of studies comparing, HBP, LBBP, and RVP as a primary pacing strategy for patients required permanent pacemaker $A F$ atrial fibrillation, $A V$ atrioventricular, $B i V P$ biventricular pacing, $E C G$ electrocardiogram, $E F$ ejection fraction, $F U$ follow-up, $H B P$ his bundle pacing, $H F H$ heart failure hospitalization, $L B B P$ left bundle branch pacing, $L V E F$ left ventricular ejection fraction, $L V E S V$ left ventricular end-systolic volume, $N A$ not available, $R C T$ randomized control trial, $R V P$ right ventricular pacing, $S N D$ sick node disease

\section{Results}

In total, 848 studies were identified from the systematic review and an additional 7 were found by references review of the included articles. After the removal of duplicates, 641 studies remained and were evaluated against the predefined inclusion criteria. Of those, 53 studies were included for full-text review, and a further 46 studies were excluded leaving 9 studies ( 7 from the databases search) for the systematic review and meta-analysis (Fig. 1). Of the 9 studies, 5 compared HBP with RVP ( $n=619$ vs. $n=905$ patients) with follow-up durations between 12 and 60 months [12, 15-18] and 4 compared LBBP with RVP ( $n=149$ vs. $n=144$ patients) with follow-up durations between 3 and 6 months [19-22]. The pacing indication was sinus node disease (SND) in 1 study, AV conduction disease in 2 study and SND and AV conduction disease in 6 studies. The characteristics of the studies are summarized in Table 1.

Result of the pairwise comparisons against RVP analysed as a single entity are detailed below:

\section{HBP compared with RVP}

\section{Mortality and HFH}

Compared with RVP, HBP was associated with a decreased risk of HFH (RR: $0.68,95 \%$ CI $0.49-0.94, p=0.02$ ) and no statistically significant difference in all-cause mortality compared with RVP (RR: $0.80,95 \%$ CI $0.63-1.02, p=0.07$ ) (Fig. 2).

\section{LVEF}

In studies that reported the change in LVEF [15-17], a decrease in LVEF was associated with RVP (mean difference (MD) $-5.72,95 \% \mathrm{CI}-7.64$ to $-3.79, p=<0.001$ ) but not for HBP (MD $0.81,95 \% \mathrm{CI}-1.23$ to $2.85, p=0.44$ ) (Fig. 3), and there was a statistically significant interaction between RVP and HBP concerning their effects on LVEF ( $p$ for interaction $<0.001$ ). 


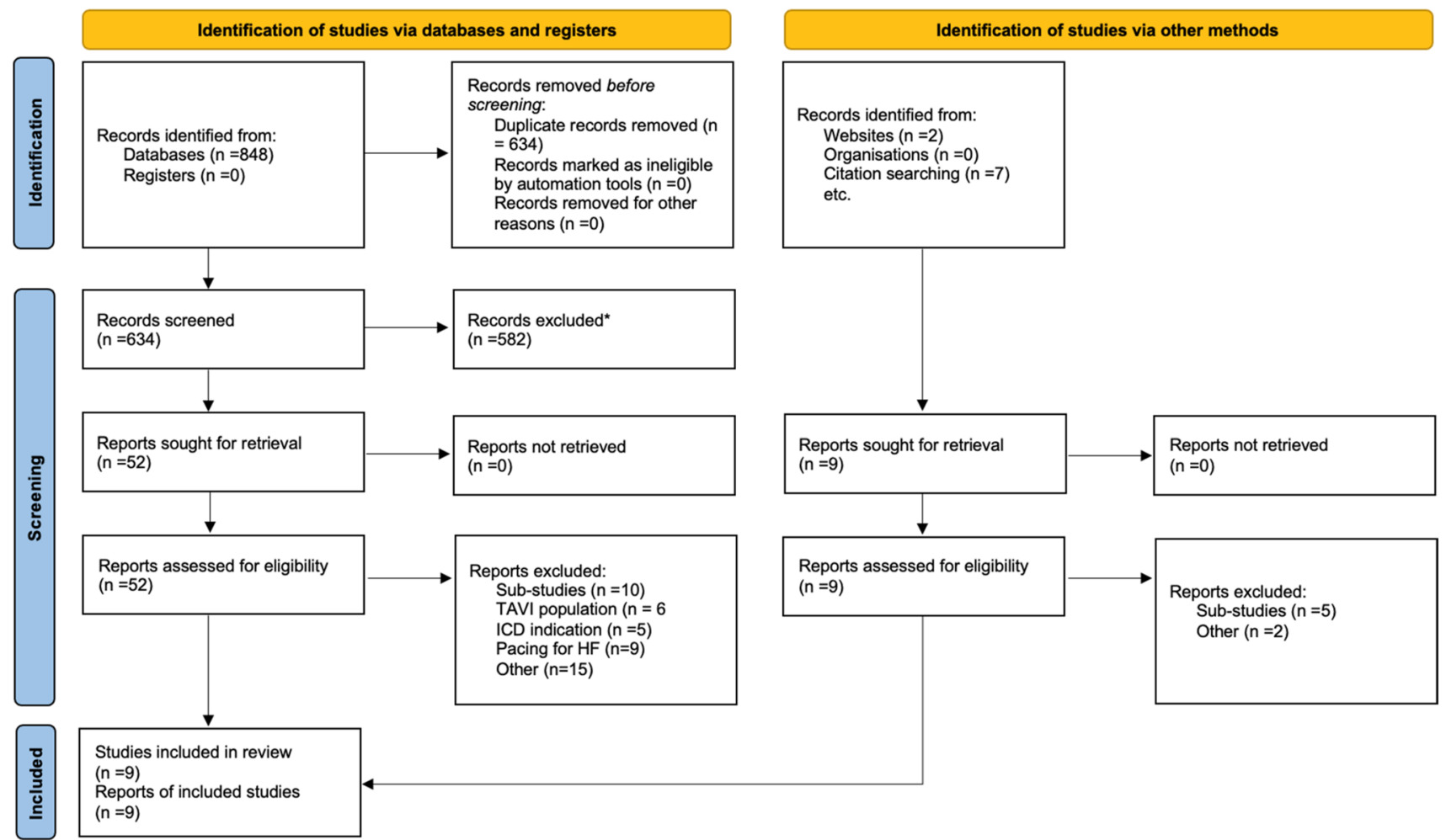

Fig. 1 PRISMA flowchart for the studies included and reasons for studies excluded from the systematic review. $H F$ heart failure, ICD implantable cardioverter defibrillator, TAVI transcatheter aortic valve implantation

\section{Incident AF}

Compared with RVP, HBP was associated with a decreased risk of new-onset AF (RR 0.61, 95\% CI 0.42-0.89, $p=0.01)$ (Fig. 3).

\section{pQRS duration}

The pQRS duration was longer in the RVP group compared with the HBP group (MD of $61.06 \mathrm{~ms}, 95 \% \mathrm{CI}$ 53.98-68.14 ms) vs. $18.37 \mathrm{~ms}$ (95\% CI 11.26-25.47 ms), respectively (Fig. 4). This was also reflected as a significant difference in the test for subgroup difference between HBP and RVP $(p<0.001)$.

\section{Procedure and fluoroscopy duration}

HPB was associated with significantly longer procedure and fluoroscopy duration compared with RVP (MD of
$15.17 \mathrm{~min}, 95 \% \mathrm{CI} 11.30-19.04)$ vs. $2.86 \mathrm{~min}(95 \% \mathrm{CI}$ 2.04-3.68) $(p<0.001)$, respectively (Fig. 5).

\section{Lead revisions}

During follow-up, ventricular lead revision was more frequently required in the HBP group compared with RVP group (RR: 5.83, 95\% CI 2.17-15.70, $p=0.0005$ ). The most common lead complication in HBP group was a progressive increase in the His capture threshold (14/426) followed by loss of capture (8/426) (Fig. 3).

\section{LBBP vs RVP}

\section{pQRS duration}

Following implantation, the pQRS duration was shorter in the LBBP group (MD $5.6 \mathrm{~ms}, 95 \% \mathrm{CI}-6.4$ to $17.6 \mathrm{~ms}$, $p=0.36)$ compared with the RVP group $(51.0 \mathrm{~ms}, 95 \% \mathrm{CI}$ 39.2-62.9 ms, $p<0.001$ ) (Fig. 4). There was a significant interaction between LBBP and HBP concerning the effect on QRS duration ( $p$ for interaction $<0.001$ ). 


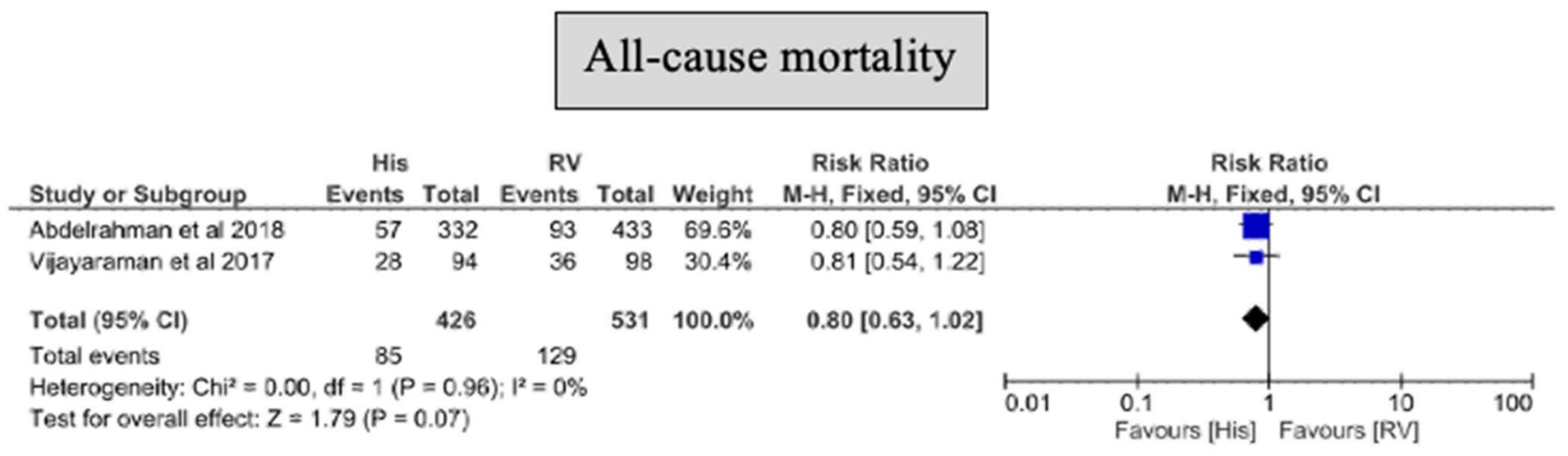

\section{$\mathrm{HFH}$}

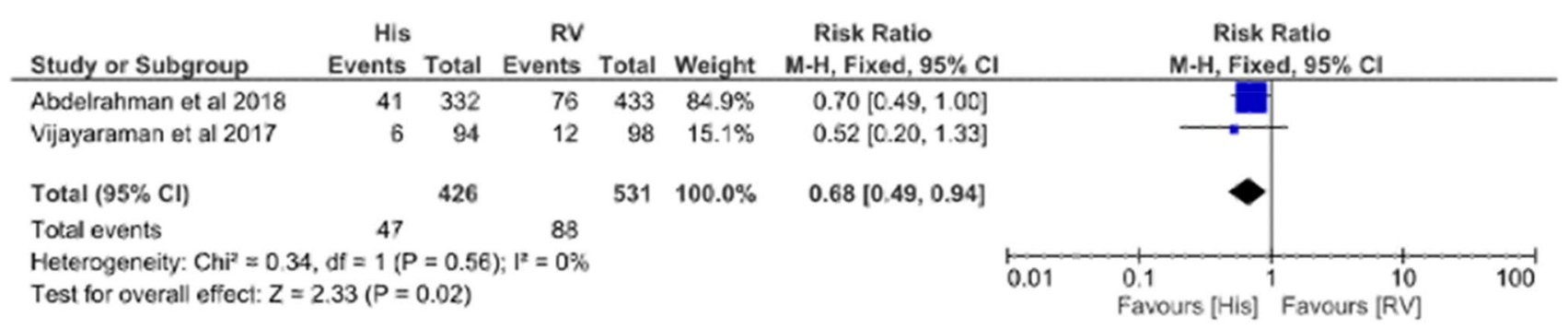

Fig. 2 Forest plot of all-cause mortality and HFH with HBP vs RVP for patients requiring permanent transvenous pacing after a 24-60 months follow-up. $C I$ confidence interval, $H B P$ His-bundle pacing, $H F H$ heart failure hospitalization, $R R$ risk reduction, $R V P$ right ventricular pacing

\section{Capture threshold}

There was no difference in pacing capture thresholds in the LBBP group compared with RVP at the time of implantation (MD of $0.02 \mathrm{~V}, 95 \% \mathrm{CI}-0.13$ to $0.17, p=0.79$ ), and at 3 months after implantation (MD of $0.03 \mathrm{~V}, 95 \% \mathrm{CI}$ -0.08 to $0.15, p=0.57$ ) (Fig. 6).

\section{Ventricular impedance and $R$ wave amplitude at implantation}

There was no difference in ventricular impedance and $\mathrm{R}$ wave amplitude in the LBBP group compared with RVP at the time of implantation (MD 4.65 Ohms, 95\% CI - 20.91 to $30.20, p=0.72$ ) and (MD $0.47 \mathrm{mV}, 95 \% \mathrm{CI}-0.89$ to $1.82, p=0.50$ ), respectively (Fig. 6).

\section{Procedure and fluoroscopy duration}

LBBP was associated with longer procedure and fluoroscopy durations compared to RVP (MD of $37.8 \mathrm{~min}$,
95\% CI 20.0-55.5) vs. (MD $11.9 \mathrm{~min}, 95 \%$ CI 10.4-13.4) $(p=<0.001)$ respectively (Fig. 5).

\section{Discussion}

This systematic review and meta-analysis aimed to evaluate the existing evidence comparing HBP or LBBP with RVP as a primary pacing strategy. We found that compared with RVP, HBP was associated with a decrease in HFH rate, a decrease in the duration of the pQRS complex and a preservation of the LVEF, though this was at the expense of higher rates of lead revision and prolonged procedure and fluoroscopy duration. This study also found that LBBP was associated with a shorter $\mathrm{pQRS}$ complex duration compared with RVP, with no differences in pacing capture threshold at implantation and at 3 months, ventricular impedance and $\mathrm{R}$ wave amplitude at implantation, but an increase in procedure and fluoroscopy duration. We are not aware of other studies that have synthesized the comparative evidence for new pacing modalities including LBBP compared with RVP.

The risk of pacemaker-induced cardiomyopathy (PICM) is associated with a high burden of the pacing of the right 


\section{LVEF change}

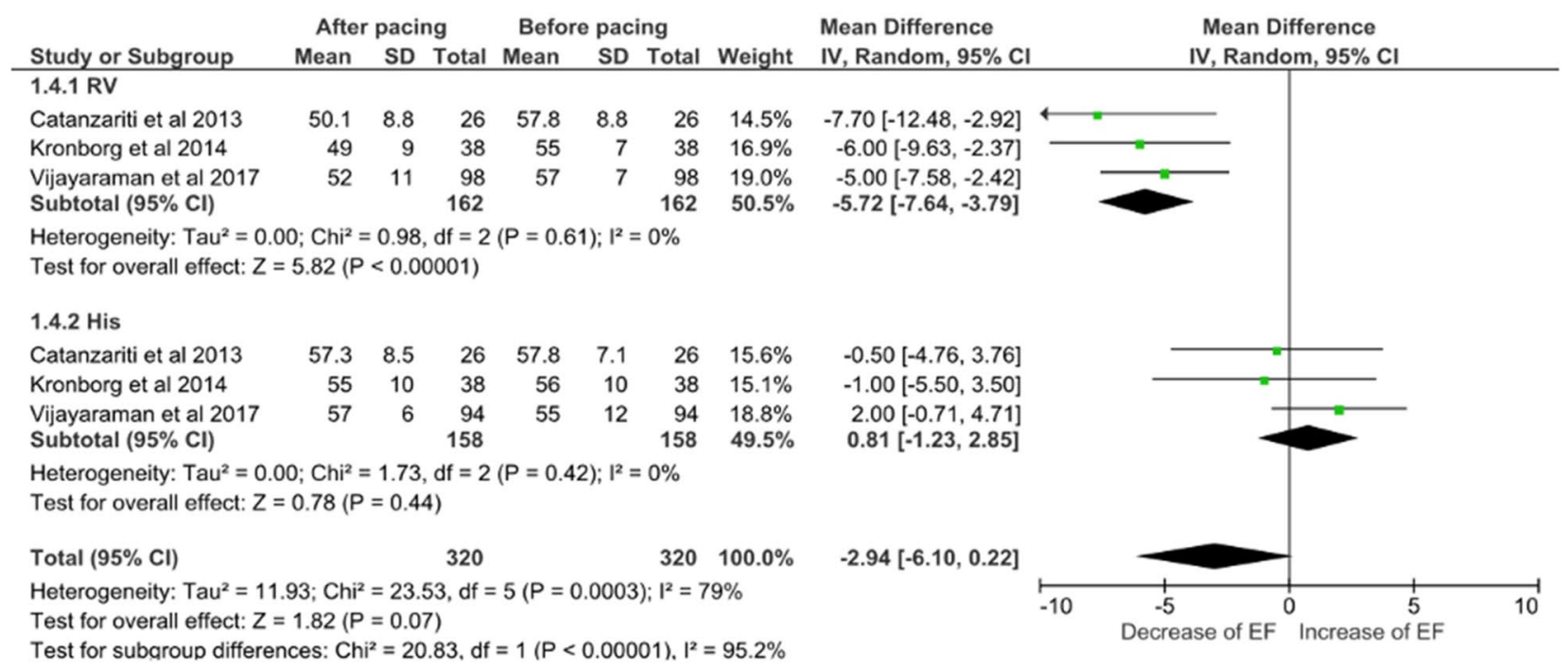

\section{Incident $\mathrm{AF}$}

\begin{tabular}{|c|c|c|c|c|c|c|c|c|c|c|}
\hline Study or Subgroup & $\begin{array}{r}\text { His } \\
\text { Events }\end{array}$ & Total & $\begin{array}{r}\text { RV } \\
\text { Events }\end{array}$ & Total & Weight & $\begin{array}{l}\text { Risk Ratio } \\
\text { M-H, Fixed, } 95 \% \mathrm{Cl}\end{array}$ & & $\begin{array}{r}\text { Risk } \\
\text { M-H, Fixe }\end{array}$ & $\begin{array}{l}\text { Ratio } \\
\text { ed, } 95 \% \mathrm{Cl}\end{array}$ & \\
\hline Kronborg et al 2014 & 0 & 19 & 3 & 19 & $5.5 \%$ & $0.14[0.01,2.59]$ & 4 & & & \\
\hline Pastore et al 2015 & 25 & 148 & 89 & 329 & $86.8 \%$ & $0.62[0.42,0.93]$ & & & & \\
\hline Vijayaraman et al 2017 & 4 & 94 & 5 & 98 & $7.7 \%$ & $0.83[0.23,3.01]$ & & & & \\
\hline Total $(95 \% \mathrm{Cl})$ & & 261 & & 446 & $100.0 \%$ & $0.61[0.42,0.89]$ & & & & \\
\hline Total events & 29 & & 97 & & & & & & & \\
\hline \multicolumn{7}{|c|}{$\begin{array}{l}\text { Heterogeneity: } \mathrm{Chi}^{2}=1.20, \mathrm{df}=2(P=0.55) ; \mathrm{I}^{2}=0 \% \\
\text { Test for overall effect: } Z=2.54(P=0.01)\end{array}$} & 0.01 & $\begin{array}{l}0.1 \\
\text { Favours [His] }\end{array}$ & $\begin{array}{l}10 \\
\text { Favours }[\mathrm{RV}]\end{array}$ & 100 \\
\hline
\end{tabular}

\section{Lead revisions}

\begin{tabular}{|c|c|c|c|c|c|c|c|c|c|}
\hline \multirow{2}{*}{$\frac{\text { Study or Subgroup }}{\text { Abdelrahman et al } 2018}$} & \multirow{2}{*}{$\begin{array}{r}\begin{array}{r}\text { His } \\
\text { Events }\end{array} \\
14\end{array}$} & & \multicolumn{2}{|l|}{ RV } & \multicolumn{2}{|r|}{ Risk Ratio } & \multicolumn{2}{|c|}{$\begin{array}{c}\text { Risk Ratio } \\
\text { M-H, Fixed, } 95 \% \mathrm{Cl}\end{array}$} & \\
\hline & & 332 & 2 & 433 & $41.4 \%$ & $9.13[2.09,39.89]$ & & 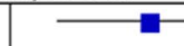 & \\
\hline Kronborg et al 2014 & 3 & 19 & 0 & 19 & $11.9 \%$ & $7.00[0.39,126.92]$ & & & \\
\hline Vijayaraman et al 2017 & 5 & 94 & 2 & 98 & $46.7 \%$ & $2.61[0.52,13.11]$ & & & \\
\hline Total $(95 \% \mathrm{Cl})$ & & 445 & & 550 & $100.0 \%$ & $5.83[2.17,15.70]$ & & & \\
\hline Total events & 22 & & 4 & & & & & & \\
\hline $\begin{array}{l}\text { Heterogeneity: } \mathrm{Chi}^{2}=1.3 \\
\text { Test for overall effect: } \mathrm{Z}\end{array}$ & $\begin{array}{l}\mathrm{df}=2(\mathrm{P} \\
3.49(\mathrm{P}=\end{array}$ & $\begin{array}{l}=0.52 \\
0.0005\end{array}$ & $; I^{2}=0 \%$ & & & 0.01 & $\begin{array}{l}0.1 \\
\text { Favours [His] }\end{array}$ & $\begin{array}{cr}1 & 10 \\
\text { Favours [RV] }\end{array}$ & 100 \\
\hline
\end{tabular}

Fig. 3 Secondary outcomes for HBP vs. RVP after 12-60 months follow-up. LVEF change from baseline, new-onset $\mathrm{AF}$ and lead revisions. $A F$ atrial fibrillation, $C I$ confidence interval, $H B P$ His-bundle pacing, $L V E F$ left ventricular ejection fraction, $R R$ risk reduction, $R V P$ right ventricular pacing 


\section{HBP vs. RVP}

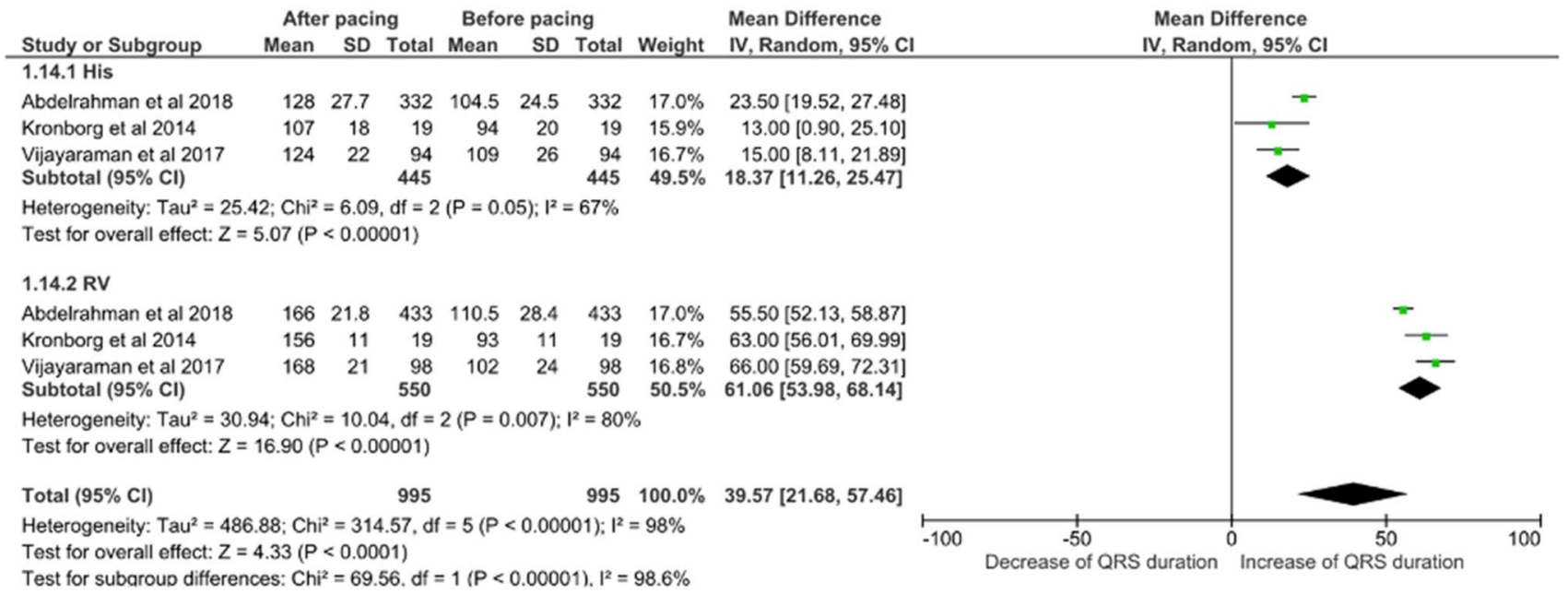

\section{LBBP vs. RVP}

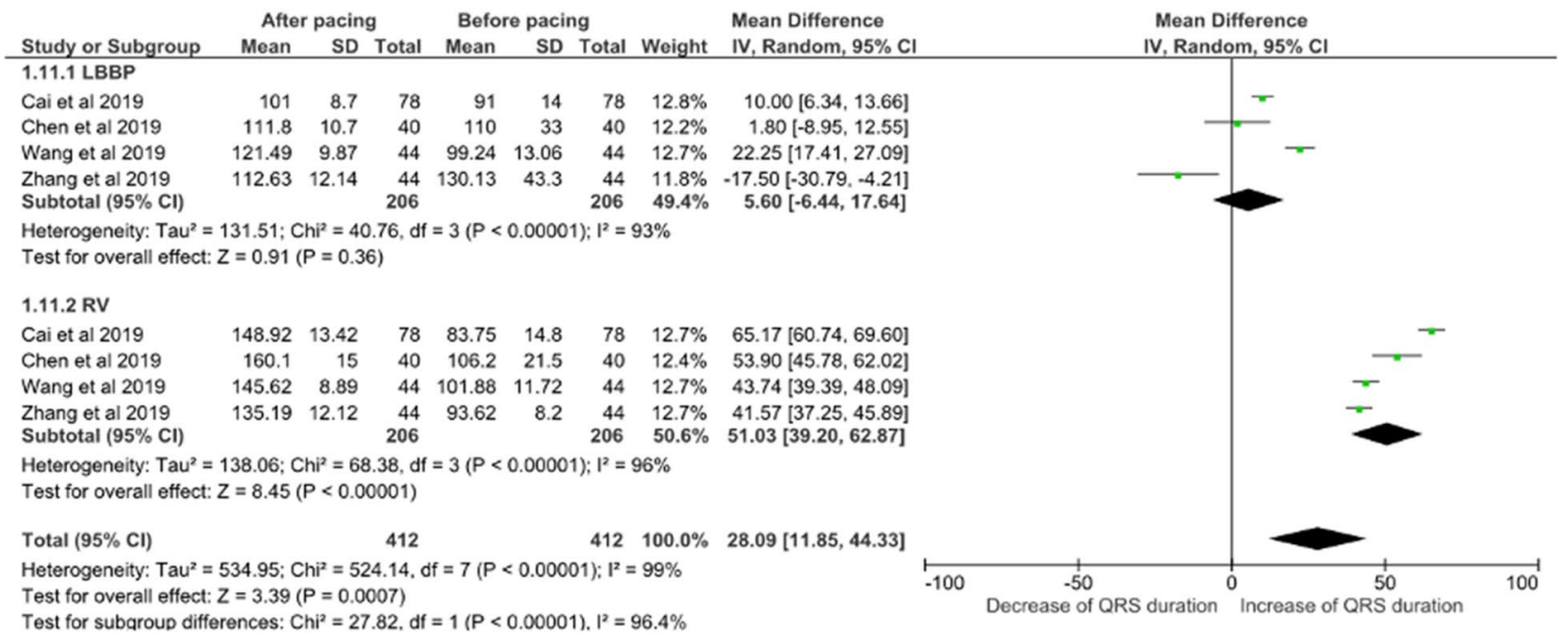

Fig. 4 Forest plot of change in QRS duration before and after implantation among HBP and LBBP groups. $C I$ confidence interval, $H B P$ Hisbundle pacing, $L B B P$ left bundle branch pacing, $R R$ risk reduction, $R V P$ right ventricular pacing

ventricle $[2,6,23]$. PICM is generally defined as the deterioration of $\mathrm{LVEF}$ by at least $10 \%$, resulting in $\mathrm{LVEF}<50 \%$, regardless of heart failure symptoms [2, 6]. Both BiVP and HBP may be effective in preventing or reversing PICM [17,
23-25]. Our study showed that HBP as an initial pacing strategy for patients requiring a permanent pacemaker is associated with a decrease in the risk of $\mathrm{HFH}$, a reduction in pQRS complex duration, and a preservation of LVEF when 


\section{HBP vs. RVP}

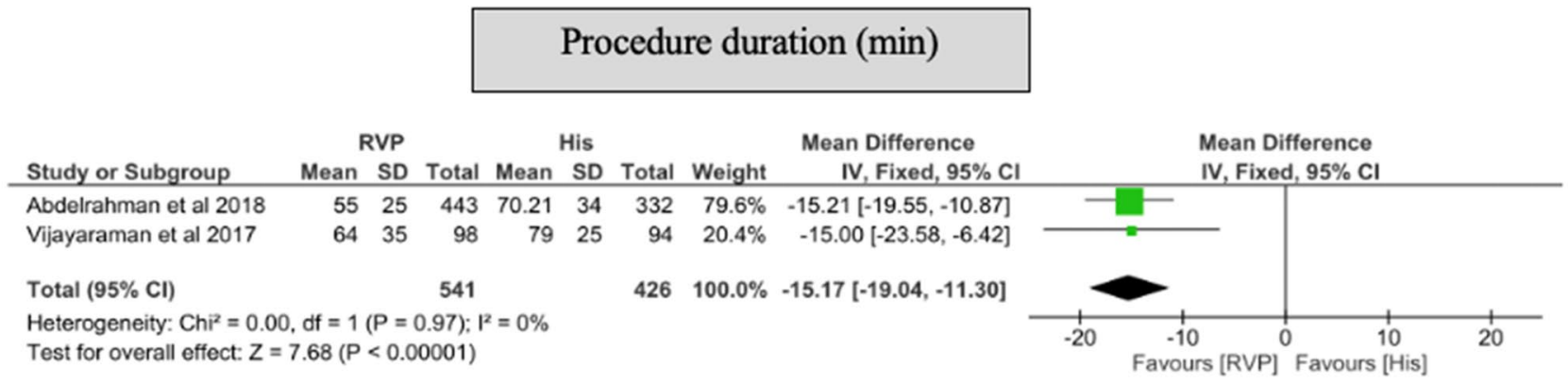

\section{Fluoroscopy duration (min)}

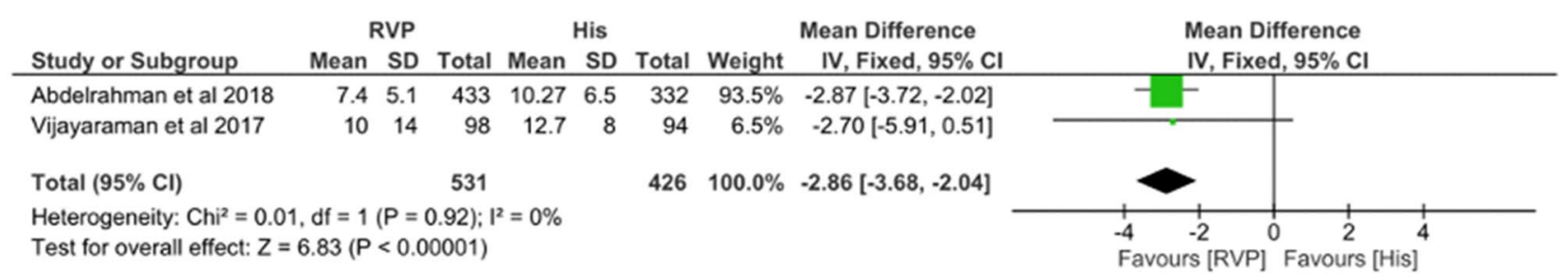

\section{LBBP vs. RVP}

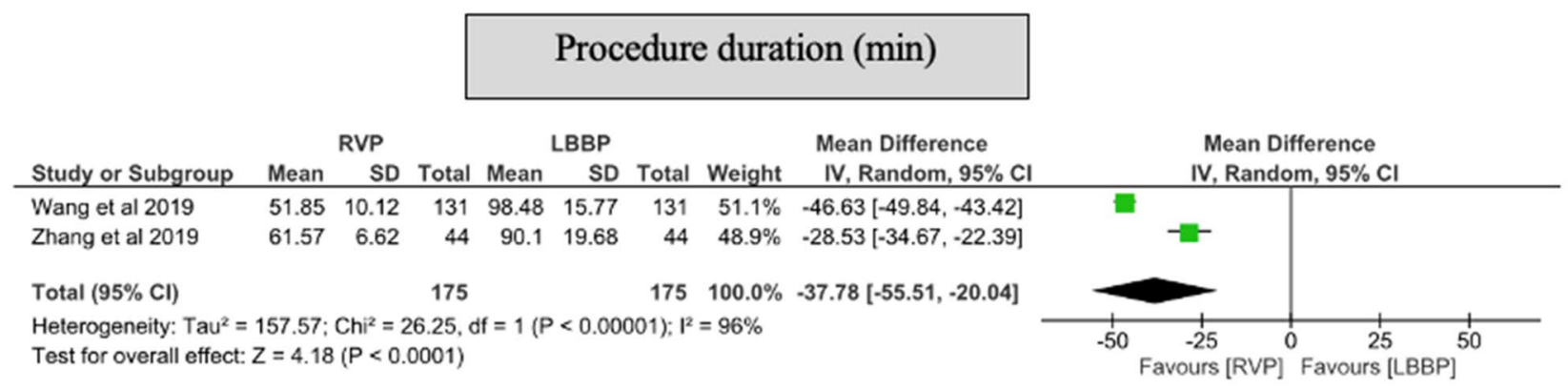

\section{Fluoroscopy duration (min)}

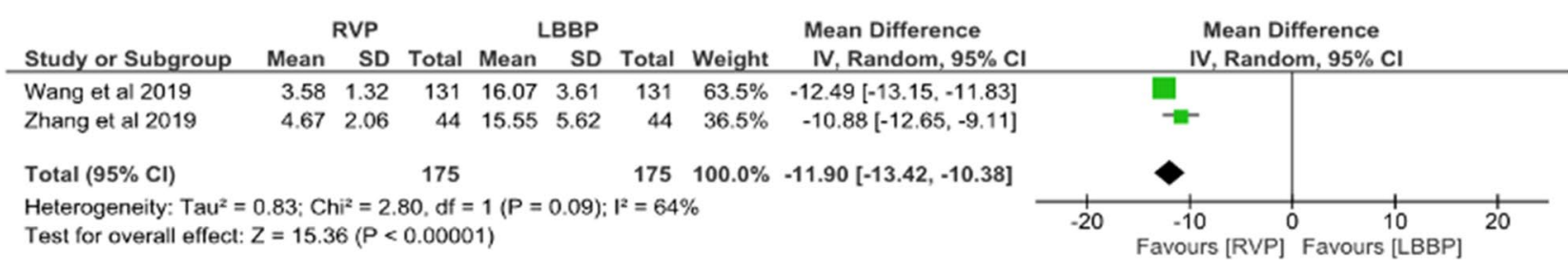

Fig. 5 Forest plot of procedure and fluoroscopy among HBP and LBBP groups. $C I$ confidence interval, $H B P$ His-bundle pacing, $L B B P$ left bundle branch pacing, $R R$ risk reduction, $R V P$ right ventricular pacing 
compared with RVP. Of note, the difference in HFH rate might be due to different baseline LVEF and the cumulative rate of ventricular pacing (different cut-offs). Thus, this finding must be interpreted with caution, until the point that robust evidence is provided.

The duration of the $\mathrm{pQRS}$ complex is considered a strong predictor for the development of PICM regardless of pacing site, particularly when its duration is longer than $140 \mathrm{~ms}$ $[2,26]$. A long pQRS duration contributes to electrical and mechanical desynchrony, which in turn leads to a deterioration of the LVEF [2-6]. Kim et al. found that a pQRS duration of $>140 \mathrm{~ms}$ was $95 \%$ sensitive for the detection of PICM while a pQRS duration of $>167$ was $90 \%$ specific for the development of PICM [25]. In our analysis, both HBP and LBBP were associated with a significantly shorter pQRS duration compared with RVP. This finding may be explained by the physiological ventricle depolarization through HisPurkinje system which leads to a narrower pQRS duration and consequently reduces desynchrony $[3,16]$.

Others have performed meta-analyses that compare RVP with BiVP or HBP for patients with a normal or mildly reduced LVEF. One analysis compared HBP versus RVP on the measurements of left ventricular dimensions, LVEF, and symptom burden [10]. However, the studies included in this analysis reported outcomes among patients with LVEF $>35 \%$ who required permanent pacing because of AV block, and data on HFH were not available. The authors reported that LVEF remained preserved or increased with BiVP and HBP compared with RVP, with no observed effect on mortality. Our analysis included a larger cohort of patients and a new study for HBP [12]. Thus, our study reports data on mortality and HFH. Fernandes et al. performed a systematic review with network meta-analysis comparing HBP, BiVP, and RVP as a primary pacing strategy for advanced AV conduction disease in patients with normal or mildly reduced EF (>40\%) [11]. This study found that $\mathrm{HBP}$ and BiVP were associated with a reduction in allcause mortality and HFH compared with RVP. HBP was superior to RVP with regards to LVEF deterioration, $\mathrm{LV}$ volumes, 6-minute walk, and pQRS duration. However, this analysis only included patients with AV conduction disease and did not report data on lead revisions, new-onset $\mathrm{AF}$ and procedure duration or LBBP as an initial pacing strategy as we do in our study. Notably, in our study, we did not compare RVP with BiVP as an initial pacing strategy because of a small number of studies available in our study period.

Our meta-analysis reported data on mortality, HFH, LVEF changes, $\mathrm{pQRS}$ duration, AF occurrence, procedure duration and rates of lead revisions. Additionally, we included studies assessing LBBP as an initial pacing strategy compared with RVP. However, due to a small number of patients and outcomes evaluated in these studies, we only report data concerning pacing metrics and $\mathrm{pQRS}$ duration between LBBP and RVP. Our results indicate the potential advantages of conduction system pacing for patients requiring permanent pacing for bradycardia. Nonetheless, it is still not clear whether HPB might be beneficial in pure SND when RV stimulation is unnecessary. Additionally, raw patient data are needed to allow a better evaluation of patient characteristics. From mainly observational data, we found that HBP or LBBP are potentially superior to RVP as a first-line approach. However, there was a paucity of information about long-term efficacy and safety for these pacing-modalities.

This study has limitations. First, the majority of the studies included in the meta-analysis had small numbers of patients, different follow-up periods and predominantly were non-randomized single center studies. Of note, the reduction in HFH reported in our analysis was based on nonrandomized studies comparing HBP performed in centres very experienced in HBP procedures with RVP performed in another centre, using RVP as routine $[12,17]$. Second, the variation in the definitions between studies particularly those pertinent to exposure (e.g., pacing rate) or the outcome measures might have caused misclassification bias. As such, investigations were performed in patients with various pacemaker indications. In some, advanced AV block or at least the expectation of high cumulative pacing rates were mandatory to be included in the study, others preferred SND to avoid complications from potentially unreliable ventricular capture with HBP. Third, our analysis does not evaluate long-term performance of LBBP, with unknown feasibility of LBBP lead complication and extraction. Fourth, there was no available data on the clinical outcome of LBBP compared to RVP. When such data on long-term efficacy and safety are available, this may become a novel recommendation, given that current guidelines only recommend RVP as the pacing strategy for patients with preserved EF $(1,7)$. Fifth, there are no data available directly comparing clinical outcomes of HBP with LBBP which limits the ability to perform a network analysis between these strategies. Sixth, there were insufficient data to conduct a meaningful comparison between HBP or LBBP and RVP according to the position of the RV lead.

\section{Conclusion}

Among patients undergoing de novo transvenous pacemaker implantation for bradyarrhythmia, an initial strategy of conduction system pacing compared with RVP was associated with shorter $\mathrm{pQRS}$ duration and preserved LVEF, but increased rates of lead revisions. LBBP compared with RVP was associated with a significant shorter $\mathrm{pQRS}$ duration with no difference in pacing metrics. Well conducted and robust randomised controlled comparative studies are 


\section{Pacing threshold at implantation}

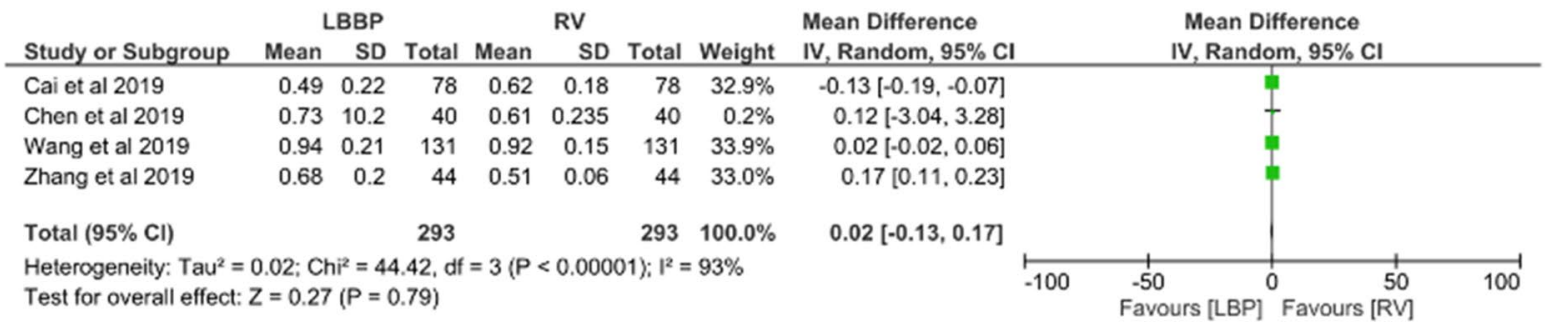

\section{Pacing threshold at 3 months}

\begin{tabular}{|c|c|c|c|c|c|c|c|c|c|c|}
\hline \multirow[b]{2}{*}{ Study or Subgroup } & \multicolumn{3}{|c|}{ LBBP } & \multicolumn{3}{|c|}{ RVP } & \multirow[b]{2}{*}{ Weight } & \multirow{2}{*}{$\begin{array}{l}\text { Mean Difference } \\
\text { IV, Random, } 95 \% \mathrm{Cl}\end{array}$} & \multirow{2}{*}{$\begin{array}{l}\text { Mean Difference } \\
\text { IV, Random, } 95 \% \mathrm{Cl}\end{array}$} & \\
\hline & Mean & SD & Total & Mean & SD & Total & & & & \\
\hline Chen et al 2019 & 0.69 & 0.14 & 40 & 0.6 & 0.19 & 40 & $53.2 \%$ & $0.09[0.02,0.16]$ & & \\
\hline Wang et al 2019 & 0.74 & 0.24 & 44 & 0.77 & 0.21 & 44 & $46.8 \%$ & $-0.03[-0.12,0.06]$ & & \\
\hline Total $(95 \% \mathrm{Cl})$ & & & 84 & & & 84 & $100.0 \%$ & $0.03[-0.08,0.15]$ & & \\
\hline \multicolumn{9}{|c|}{$\begin{array}{l}\text { Heterogeneity: } \text { Tau }^{2}=0.01 ; \mathrm{Ch}^{2}=3.89, \mathrm{df}=1(P=0.05) ; \mathrm{I}^{2}=74 \% \\
\text { Test for overall effect: } Z=0.56(P=0.57)\end{array}$} & $\begin{array}{ccc}-1 & 0 \\
\text { Favours LBBP } & \text { Favours RV }\end{array}$ & $\begin{array}{l}1 \\
\text { VP }\end{array}$ \\
\hline
\end{tabular}

\section{Ventricular impedance (Ohms)}

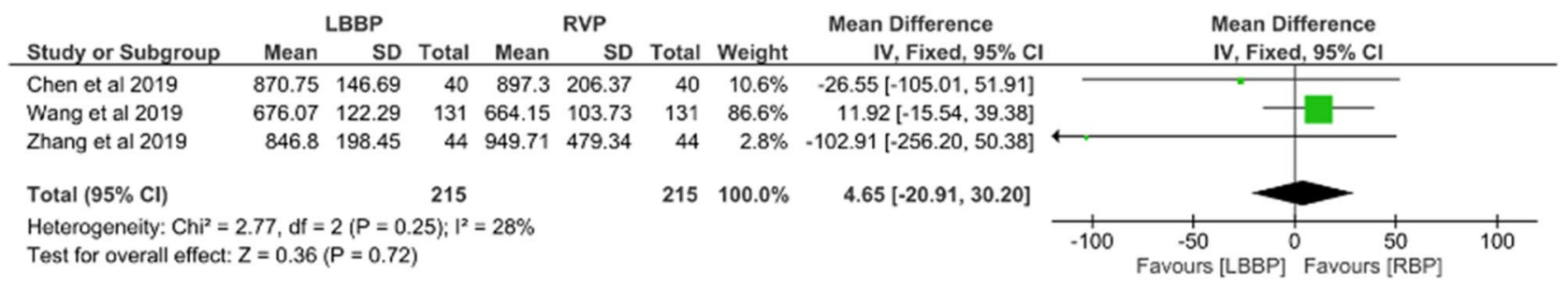

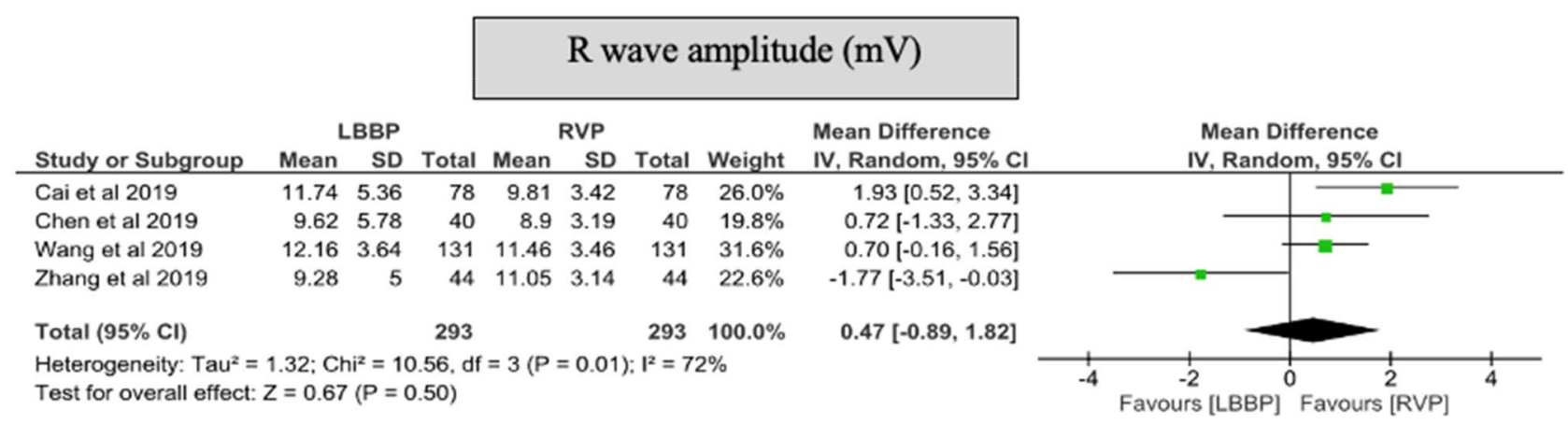


4Fig. 6 Forest plot of change in pacing threshold at implantation and at 3 months, ventricular impedance and $\mathrm{R}$ wave amplitude at implantation among LBBP and RVP groups. $C I$ confidence interval, $L B B P$ left bundle branch pacing, $R R$ risk reduction, $R V P$ right ventricular pacing

needed to prove clinical outcome benefits from conduction system pacing.

Funding Open Access funding enabled and organized by Projekt DEAL. No funding to declare.

Data availability The data underlying this article are available in the article and in its online supplementary material.

\section{Declarations}

Conflict of interest HB received honoraria for lectures and scientific advice from Boston Scientific and Medtronic. MG is supported by grants from Biotronik, Pfizer and Philips and received honoraria for Boston Scientific. JC Nielsen is supported by grants from the Novo Nordisk Foundation (NNF16OC0018658 and NNF17OC0029148). $\mathrm{CU}$ has received honoraria for lectures and scientific advice from Bayer, Boehringer-Ingelheim, Medtronic, Pfizer, ReCor Medical. KV is supported by grants from the Abbott and Medtronic and received honoraria for lectures and scientific advice from Abbott, Boston Scientific and Medtronic. CPG is supported by grants from the Abbott and BMS and received honoraria for lectures and scientific advice from Amgen and AstraZeneca. AA, SA, DV, EA, CM and TM: none declared.

Open Access This article is licensed under a Creative Commons Attribution 4.0 International License, which permits use, sharing, adaptation, distribution and reproduction in any medium or format, as long as you give appropriate credit to the original author(s) and the source, provide a link to the Creative Commons licence, and indicate if changes were made. The images or other third party material in this article are included in the article's Creative Commons licence, unless indicated otherwise in a credit line to the material. If material is not included in the article's Creative Commons licence and your intended use is not permitted by statutory regulation or exceeds the permitted use, you will need to obtain permission directly from the copyright holder. To view a copy of this licence, visit http://creativecommons.org/licenses/by/4.0/.

\section{References}

1. Brignole M, Auricchio A, Baron-Esquivias G, Bordachar P, Boriani G, Breithardt OA et al (2013) ESC Guidelines on cardiac pacing and cardiac resynchronization therapy: The Task Force on cardiac pacing and resynchronization therapy of the European Society of Cardiology (ESC). Developed in collaboration with the European Heart Rhythm Association (EHRA). Eur Heart J 34:2281-2329

2. Abdin A, Yalin K, Zink MD, Napp A, Gramlich M, Marx N, Schuett K (2019) Incidence and predictors of pacemaker induced cardiomyopathy: a single-center experience. J Electrocardiol 57:31-34

3. Lewis AJM, Foley P, Whinnett Z, Keene D, Chandrasekaran B (2019) His bundle pacing: a new strategy for physiological ventricular activation. J Am Heart Assoc 19(8):e010972
4. Khurshid S, Epstein AE, Verdino RJ, Lin D, Goldberg LR, Marchlinski FE, Frankel DS (2014) Incidence and predictors of right ventricular pacing-induced cardiomyopathy. Heart Rhythm 11:1619-1625

5. Dreger H, Maethner K, Bondke H, Baumann G, Melzer C (2012) pacing induced cardiomyopathy in patients with right ventricular stimulation for $>15$ years. Europace 14:238-242

6. Kiehl EL, Makki T, Kumar R, Gumber D, Kwon DH, Rickard JW et al (2016) Incidence and predictors of right ventricular pacinginduced cardiomyopathy in patients with complete atrioventricular block and preserved left ventricular systolic function. Heart Rhythm 13:2272-2278

7. Kusumoto FM, Schoenfeld MH, Barrett C, Edgerton JR, Ellenbogen KA, Gold MR et al (2019) 2018 ACC/AHA/HRS Guideline on the evaluation and management of patients with bradycardia and cardiac conduction delay: a report of the American college of cardiology/American heart association task force on clinical practice guidelines, and the Heart Rhythm Society. J Am Coll Cardiol 74:e51-e156

8. Curtis AB, Worley SJ, Adamson PB, Chung ES, Niazi I, Sherfesee $L$ et al (2013) Biventricular pacing for atrioventricular block and systolic dysfunction. N Engl J Med 368:1585-1593

9. Vijayaraman P, Bordachar P, Ellenbogen KA (2017) The continued search for physiological pacing. Where are we now? J Am Coll Cardiol 69:3099-3114

10. Slotwiner DJ, Raitt MH, Munoz FD, Mulpuru SK, Nasser N, Peterson PM et al (2019) Impact of physiologic pacing versus right ventricular pacing among patients with left ventricular ejection fraction greater than $35 \%$ : a systematic review for the $2018 \mathrm{ACC} / \mathrm{AHA} / \mathrm{HRS}$ guideline on the evaluation and management of patients with bradycardia and cardiac conduction delay: a report of the American college of cardiology/American heart association task force on clinical practice guidelines and the Heart Rhythm Society. J Am Coll Cardiol 74(7):988-1008

11. Fernandes GC, Knijnik L, Lopez J, Rivera M, Fernandes A, Lambrakos LK et al (2020) Network meta-analysis of His bundle, biventricular, or right ventricular pacing as a primary strategy for advanced atrioventricular conduction disease with normal or mildly reduced ejection fraction. J Cardiovasc Electrophysiol 31:1482-1492

12. Abdelrahman M, Subzposh FA, Beer D, Durr B, Naperkowski A, Sun H et al (2018) Clinical outcomes of his bundle pacing compared to right ventricular pacing. J Am Coll Cardiol 71:2319-2330

13. Nielsen JC, Glikson M et al (2021) European Society of Cardiology (ESC) Clinical practice guidelines on cardiac pacing and cardiac resynchronization therapy

14. Hutton B, Salanti G, Caldwell DM, Chaimani A, Schmid CH, Cameron $\mathrm{C}$ et al (2015) The PRISMA extension statement for reporting of systematic reviews incorporating network metaanalyses of health care interventions: checklist and explanations. Ann Intern Med 162:777-784

15. Catanzariti D, Maines M, Manica A, Angheben C, Varbaro A, Vergara G (2013) Permanent His-bundle pacing maintains longterm ventricular synchrony and left ventricular performance, unlike conventional right ventricular apical pacing. Europace 15:546-553

16. Kronborg MB, Mortensen PT, Poulsen SH, Gerdes JC, Jensen HK, Nielsen JC (2014) His or para-His pacing preserves left ventricular function in atrioventricular block: a double-blind, randomized, crossover study. Europace 16:1189-1196

17. Vijayaraman P, Naperkowski A, Subzposh FA, Abdelrahman M, Sharma PS, Oren JW et al (2018) Permanent his-bundle pacing: Long-term lead performance and clinical outcomes. Heart Rhythm 15:696-702 
18. Pastore G, Zanon F, Baracca E, Aggio S, Corbucci G, Boaretto $\mathrm{G}$ et al (2016) The risk of atrial fibrillation during right ventricular pacing. Europace 18:353-358

19. Zhang J, Wang Z, Cheng L, Zu L, Liang Z, Hang F et al (2019) Immediate clinical outcomes of left bundle branch area pacing vs conventional right ventricular pacing. Clin Cardiol 42:768-773

20. Wang J, Liang Y, Wang W, Chen X, Bai J, Chen H et al (2020) Left bundle branch area pacing is superior to right ventricular septum pacing concerning depolarization-repolarization reserve. J Cardiovasc Electrophysiol 3:313-322

21. Cai B, Huang X, Li L, Guo J, Chen S, Meng F et al (2020) Evaluation of cardiac synchrony in left bundle branch pacing: insights from echocardiographic research. J Cardiovasc Electrophysiol 31:560-569

22. Chen K, Li Y, Dai Y, Sun Q, Luo B, Li C et al (2019) Comparison of electrocardiogram characteristics and pacing parameters between left bundle branch pacing and right ventricular pacing in patients receiving pacemaker therapy. Europace 21:673-680
23. Khurshid S, Obeng-Gyimah E, Supple GE, Schaller R, Lin D, Owens AT et al (2018) Reversal of pacing- induced cardiomyopathy following cardiac resynchronization therapy. JACC Clin Electrophysiol 4:168-177

24. Shan P, Su L, Zhou X, Wu S, Xu L, Xiao F et al (2018) Beneficial effects of upgrading to His bundle pacing in chronically paced patients with left ventricular ejection fraction $<50$. Heart Rhythm $15: 405-412$

25. Logue J, Vijayaraman P, Pavri B (2017) Could cardiac resynchronization via his bundle pacing reduce arrhythmic risk? Circulation 136:A16112 ((abstract))

26. Kim JH, Kang KW, Chin JY, Kim TS, Park JH, Choi JJ et al (2018) Major determinant of the occurrence of pacing-induced cardiomyopathy in complete atrioventricular block: a multicentre, retrospective analysis over a 15-year period in South Korea. BMJ Open 8:019048

\section{Authors and Affiliations}

\section{Amr Abdin $^{1}$ (1) - Suleman Aktaa ${ }^{2,3} \cdot$ Davor Vukadinović $^{1}$ - Elena Arbelo ${ }^{4,5,6} \cdot$ Harran Burri $^{7} \cdot$ Michael Glikson $^{8}$. Christian Meyer $^{9} \cdot$ Theresa Munyombwe $^{2}$. Jens Cosedis Nielsen ${ }^{10,11} \cdot$ Christian Ukena $^{1} \cdot$ Kevin Vernooy $^{12,13}$. Chris P. Gale ${ }^{2,3}$}

1 Cardiology, Angiology and Intensive Care Medicine, Internal Medicine Clinic III, Saarland University Hospital, Kirrberger Street 100, 66421 Homburg, Saarland, Germany

2 Leeds Institute of Cardiovascular and Metabolic Medicine, Faculty of Medicine and Health, University of Leeds, Leeds LS2 9JT, UK

3 Department of Cardiology, Leeds Teaching Hospitals NHS Trust, Leeds LS1 3EX, UK

4 Cardiology Department, Arrhythmia Section, Hospital Clínic, Universitat de Barcelona, C. Villarroel 170, Esc 3, Planta 6, 08036 Barcelona, Spain

5 IDIBAPS, Institut D’Investigació August Pi I Sunyer (IDIBAPS), Barcelona, Spain

6 Centro de Investigación Biomédica en Red de Enfermedades Cardiovasculares (CIBERCV), Madrid, Spain

7 Cardiology Department, Geneva University Hospital, Geneva, Switzerland
8 Cardiology Department, Shaare Zedek Hospital, affiliated to the Hebrew University, Jerusalem, Israel

9 University Heart Center, Hamburg, Cardiac Neuro- and Electrophysiology Research Consortium, EVK Düsseldorf, Düsseldorf, Germany

10 Department of Cardiology, Aarhus University Hospital, Aarhus, Denmark

11 Department of Clinical Medicine, Aarhus University, Aarhus, Denmark

12 Department of Cardiology, Cardiovascular Research Institute Maastricht (CARIM), Maastricht University Medical Center, Maastricht, The Netherlands

13 Radboud University Medical Center, Nijmegen, The Netherlands 